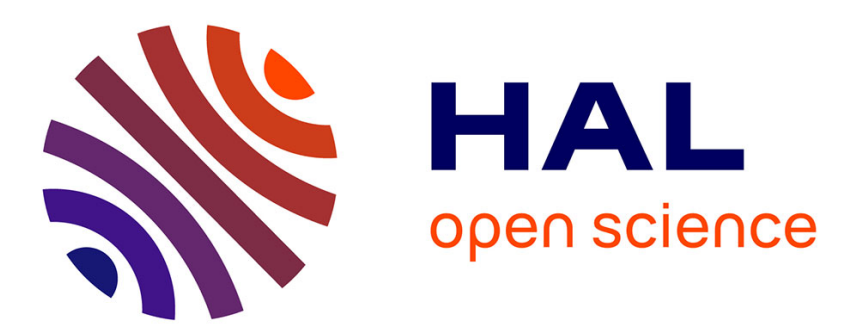

\title{
EMC behavior of static converters thanks to radiated field modeling using an equivalent electrical circuit
}

Jérémie Aimé, Vincent Ardon, Edith Clavel, James Roudet, Philippe Loizelet

\section{To cite this version:}

Jérémie Aimé, Vincent Ardon, Edith Clavel, James Roudet, Philippe Loizelet. EMC behavior of static converters thanks to radiated field modeling using an equivalent electrical circuit. IECON 2009, Nov 2009, Porto, Portugal. hal-00430247

\section{HAL Id: hal-00430247 https://hal.science/hal-00430247}

Submitted on 6 Nov 2009

HAL is a multi-disciplinary open access archive for the deposit and dissemination of scientific research documents, whether they are published or not. The documents may come from teaching and research institutions in France or abroad, or from public or private research centers.
L'archive ouverte pluridisciplinaire HAL, est destinée au dépôt et à la diffusion de documents scientifiques de niveau recherche, publiés ou non, émanant des établissements d'enseignement et de recherche français ou étrangers, des laboratoires publics ou privés. 


\title{
EMC behavior of static converters thanks to radiated field modeling using an equivalent electrical circuit
}

\author{
Jérémie AIME ${ }^{1-2}$, Vincent ARDON ${ }^{1-3}$, Edith CLAVEL ${ }^{1}$, James ROUDET ${ }^{1}$, Philippe LOIZELET ${ }^{2}$ \\ ${ }^{1}$ Grenoble Electrical Engineering Laboratory (G2ELAB) UJF-CNRS-INP, BP 46, 38402 Grenoble - France \\ ${ }^{2}$ Schneider and Toshiba Inverter Europe (STIE), 27120 Pacy sur Eure - France \\ ${ }^{3}$ Cedrat Group, 15 Chemin de Malacher - inovallée, 38246 Meylan Cedex - France \\ jeremie.aime@g2elab.grenoble-inp.fr
}

\begin{abstract}
Concerning power electronics converters, due to frequency and/or power rising, EMC constraints become more and more important for industrials and compliance with standards is not guarantee. In consequence, anticipation becomes a key word for engineers and the conception using computer aided design tools is actually more suitable. That is why, nowadays, efforts are focused on model developments. Unfortunately, modeling methods are limited by the complexity of industrial products. This complexity is due to the geometries with arbitrary shapes and to the nature of associated components (magnetic or not). This paper presents the EMC modeling of static converters with an application to a variable speed drive using integral methods. PEEC, AMLFMM methods and a circuit simulator are combined to compute the differential and common mode sources and finally the emitted field.
\end{abstract}

\section{INTRODUCTION}

Due to standards, EMC constraints need to be taken into account during the design process of a product. In consequence, many works have been carried on EMC modeling of static converters [1-3]. Nevertheless, due to their complexity, industrial structures and more specifically variable speed drives are less investigated. Everyone knows that the EMC performances of such structures can be drastically influenced by the position of components and the way they are connected together. The purpose of this article is to more particularly focus on the electrical modeling of cabling assuming the knowledge of the behavior of passive or active components. Concerning interconnections, models in conducted frequency range have been developed and are in good agreements with measurements [4]. But they are limited to the conducted frequency range. On the other hand, near field studies have also been carried on but only differential mode is taken into account [5]. This paper deals with the EMC modeling process of static converters with an application on a Schneider and Toshiba Inverter Europe (STIE) variable speed drive. Both common and differential modes are taken into account thanks to a complete electrical equivalent model and radiated field is computed. The modeling method is first presented. Then, the conducted and radiated perturbations of an academic structure are computed using the modeling process. In a third section, this process is applied to a variable speed drive in order to evaluate the radiated magnetic field and to conclude upon the EMC performances of such a structure.

\section{MODELING PROCESS}

\section{A. Introduction}

The aim of this paper is to evaluate the emitted magnetic field by using Biot and Savart law (1) in a large frequency domain in order to verify the compliance of a power electronic structure with standards.

$$
\overrightarrow{\mathrm{B}}(\mathrm{P})=\frac{\mu 0}{4 \pi} * \iiint_{\mathrm{M} \in \mathrm{V}} \frac{\overrightarrow{\mathrm{J}} \times \overrightarrow{\mathrm{MP}}}{\left\|\mathrm{MP}^{3}\right\|} \mathrm{dV}
$$

Point $\mathrm{M}$ is an element of the volume where the current density $(\mathrm{J})$ is known, here the tracks, and $\mathrm{P}$ is the field point.

Due to standards, it is also necessary to compute the electric field. This entity is deduced from the magnetic field using the wave impedance given by (2).

$$
Z(d, f)=\frac{-j \omega \mu 0 d(1+j k d)}{1+j k d-(d k)^{2}}
$$

In eq. (2) $d$ is the distance between the source and the field point, $\mathrm{k}$ is the propagation constant defined in the air by (3) in which $\mathrm{c}$ is the light speed.

$$
\mathrm{k}=\frac{\omega}{\mathrm{c}}
$$

It appears that the field is given by the current density. This variable depends on the layout topology which can be very complex and not negligible [6]. In consequence, this complexity must be taken into account in order to compute correct values of current and by this way, of emitted field too. The following part presents the developed model giving the current density by taking into account the constraints imposed by the layout topology.

\section{B. Model}

EMC perturbations of a static converter are generated by the differential and common mode currents as in $[2,3,7]$. Both currents must be taken into account in order to compute near and far fields in a large frequency domain and in the three spatial dimensions. The equivalent impedance of the converter layout is determined by considering the geometry like an equivalent electrical circuit using lumped elements. 
The differential mode is associated with resistive, inductive and mutual terms [3]. A capacitive model is added in order to model the common mode [2]. The appropriated modeling methods to compute this model are presented in the next part.

\section{Modeling methods}

Due to meshing considerations, multilayer topologies are difficult to describe using classical variational methods. Integral methods are more adapted to such problems [8]. In this case, the inductive and resistive terms are determined by using Partial Element Equivalent Circuit (PEEC) method [9]. The capacitive model is computed by using an Adaptative Multi-Level Fast Multipole Method (AMLFMM).

\section{PEEC method: resistive and inductive terms}

The Partial Element Equivalent Circuit (PEEC) method was introduced by A. Ruehli in 1972 [9]. Based on low frequency exact analytical formulas, it consists in extracting the electric parameters from geometries. Full PEEC method takes into account resistive, inductive and capacitive parts. Unfortunately, for actual power electronics converters, geometries of conductors are so complex that full PEEC models including resistive, inductive and capacitive parts are too tricky to compute. So the model has to be reduced. That is why the PEEC method is restricted to the resistive and inductive including mutual terms.

The inductance of a rectangular loop (Fig. 1) is evaluated using the circulation of potential vector (3).

$$
\mathrm{L}_{\mathrm{b}}=\frac{1}{\mathrm{i}} \oint_{\mathrm{C}} \overrightarrow{\mathrm{A}} \cdot \mathrm{d} \vec{\ell}
$$

This circulation can be decomposed along the contour into segments. Moreover, the potential vector on a segment is due to the contribution of the potential vectors of the other segments [9]. So the expression of the inductance becomes (4). In that way, partial elements can be defined: the partial inductance of each segment in (5) and the partial mutual in (6).

$$
\begin{aligned}
& \mathrm{L}_{\mathrm{b}}=\frac{1}{\mathrm{i}} \sum_{\mathrm{n}=1}^{4} \sum_{\mathrm{m}=1}^{4} \int_{\mathrm{S}_{\mathrm{n}}} \overrightarrow{\mathrm{A}}_{\mathrm{S}_{\mathrm{m}}} \cdot \mathrm{d} \vec{\ell} \\
& \mathrm{L}_{\mathrm{p}_{\mathrm{n}}}=\frac{1}{\mathrm{i}} \int_{\mathrm{S}_{\mathrm{n}}} \overrightarrow{\mathrm{A}}_{\mathrm{S}_{\mathrm{n}}} \cdot \mathrm{d} \vec{\ell} \\
& \mathrm{M}_{\mathrm{p}_{\mathrm{mn}}}=\frac{1}{\mathrm{i}} \int_{\mathrm{S}_{\mathrm{n}}} \overrightarrow{\mathrm{A}}_{\mathrm{S}_{\mathrm{m}}} \cdot \mathrm{d} \vec{\ell}
\end{aligned}
$$

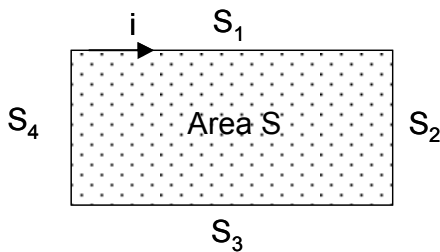

Fig. 1. Example of a rectangular loop
Finally, the inductance of the loop is given by (7).

$$
\mathrm{L}_{\mathrm{b}}=\sum_{\mathrm{n}=1}^{4} \sum_{\mathrm{m}=1}^{4} \mathrm{M}_{\mathrm{p}_{\mathrm{ij}}}
$$

In case of massive conductors, the partial inductive elements are defined by analytical formulas as in $[9,11]$ or using numerical solving, depends on the complexity of the geometry of conductors.

The same way, the partial resistances can be defined and are computed with (8).

$$
\mathrm{R}=\frac{\rho \ell}{\mathrm{S}}
$$

Using the equivalent electrical circuit, the conductors are meshed and the circuit equations are solved in order to deduce the current distributions inside the structure. The meshes are adapted in order to model the proximity and skin effects. Finally, the current knowledge allows computing the global losses of the conductors of the structure but also the magnetic field using Biot and Savart law. This method applied to a power electronic structure has shown good results on the radiated field modeling taking into account the differential mode currents [3].

In order to take into account the common mode currents, this resistive and inductive model for cabling is no more sufficient, the capacitive part has to be evaluated as well.

\section{AMLFMM method: capacitive terms}

For complex geometries, full PEEC models including capacitances are not easily computed. However, some of the capacitances can be modeled using equivalent simple capacitance localized at the electrical node where potential variation is the highest. This last component can be evaluated in a separate way without using PEEC approach. While inserting the structure inside its electrical environment, some additional parts such as ground plane imply to take into account capacitive effects. For most of the cases, the use of only some capacitances is sufficient to translate this effect if they are well connected [2].

Nevertheless a dedicated integral method can be used to compute interaction matrix which is composed of potential and normal field coefficients between each mesh cell [12]. This matrix links the charges to the potential of conductors. Charge distributions are obtained by solving a linear matrix system. The worst inconvenience of this method is the storage of the square and dense matrix.

To avoid this problem, the AMLFMM can be used to model large devices. This algorithm accelerates the computation of interaction coefficients and is low-memory consuming by using truncated multipole decomposition of interactions [13-15]. The potentials are given by (8).

$$
\Psi\left(r_{j}, \theta_{j}, \varphi_{j}\right) \approx \sum_{n=1}^{\ell} \sum_{m=-n}^{+n} A_{n}^{m} \cdot \frac{1}{r_{j}^{n+1}} \cdot Y_{n}^{m}(\theta, \varphi)
$$


In eq. (8), $\ell$ is the decomposition order, $r_{j}, \theta_{j}$ and $\varphi_{j}$ are the spherical coordinates of the point of evaluation, $\mathrm{Y}_{\mathrm{n}}{ }^{\mathrm{m}}$ and $\mathrm{A}_{\mathrm{n}}{ }^{\mathrm{m}}$, the spherical harmonics and the multipole coefficients are given by (9) and (10) respectively.

$$
\begin{gathered}
Y_{n}^{m}(\theta, \varphi)=k_{n}^{m} \cdot P_{n}^{m}(\cos \theta) \cdot e^{j m \varphi} \\
A_{n}^{m}=\sum_{i=1}^{n_{2}} q_{i} \rho_{i}{ }^{n} Y_{n}^{-m}\left(\alpha_{i}, \beta_{i}\right)
\end{gathered}
$$

In eq. (10), $\mathrm{n}_{2}$ is the number of charges, $\alpha_{\mathrm{i}}$ and $\beta_{\mathrm{i}}$ are the spherical coordinates of the charge $q_{i}$ and $k_{n}{ }^{m}$ is written as in (11) and Legendre function $\mathrm{P}_{\mathrm{n}}{ }^{\mathrm{m}}$ is defined by (12).

$$
\begin{aligned}
\mathrm{k}_{\mathrm{n}}^{\mathrm{m}} & =(-1)^{\mathrm{m}} \sqrt{\frac{2 \mathrm{n}+1}{4 \pi} \frac{(\mathrm{n}-\mathrm{m}) !}{(\mathrm{n}+\mathrm{m}) !}} \\
\mathrm{P}_{\mathrm{n}}^{\mathrm{m}}(\mathrm{z}) & =\frac{\left(1-\mathrm{z}^{2}\right)^{\frac{\mathrm{m}}{2}}}{2^{\mathrm{n}} \mathrm{n} !} \cdot \frac{\mathrm{d}^{\mathrm{n}+\mathrm{m}}}{d \mathrm{z}^{\mathrm{n}+\mathrm{m}}}\left(\mathrm{z}^{2}-1\right)^{\mathrm{n}}
\end{aligned}
$$

This method subdivides the geometry into cubes of different levels with an adaptive octree algorithm which controls the interaction computations and leads to a compact matrixvector product. Considering four conductors, with three meshes, with opposite potentials, the interactions have been computed using a dedicated integral method and AMLFMM. It appears clearly that AMLFMM is more powerful. Fewer interactions are necessary to solve the same problem (Fig. 2).

\section{Propagation}

The covered frequency range of the pollution emitted by static converters is generally limited to $200 \mathrm{MHz}$. In consequence, considering the dimensions of classical power electronic structures, propagation effects can be neglected in many cases. That is why, due to their dimensions, the cables are not taken into account in this study. However, for too long conductors, retardation is taken into account by using rPEEC method [16].

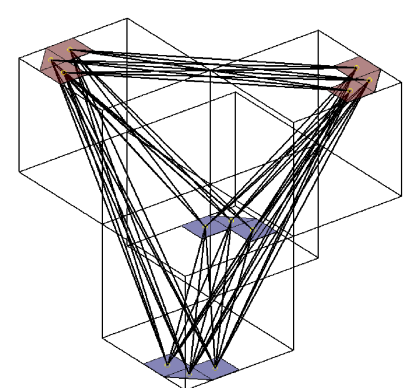

Integral method

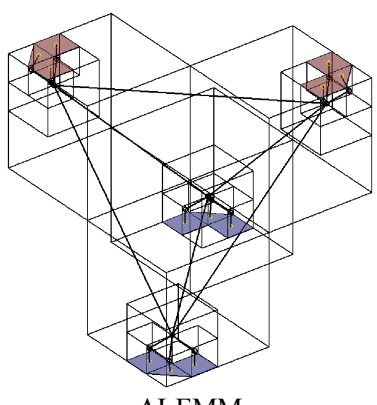

ALFMM
Fig. 2. Number of computed interactions depending on the method

\section{Modeling process}

The modeling process is presented in Fig. 3. The equivalent impedance is deduced from the topology (mechanical part and cabling) thanks to InCa3D software [17]. It is a dedicated-tool based on PEEC formulations. Then, the computed capacitances are plugged to the PEEC model of the geometry which has been designed with InCa3D. The equivalent circuit is imported into a circuit simulator like PSpice or Saber. Indeed, to compute the radiated field, the equivalent electrical circuit must be excited with current (differential mode) and voltage (common mode) sources. These sources are determined thanks to time domain simulations of the power electronic structure. By this way, the non linearity induced by the switching is modeled and the geometry, through the equivalent impedance, is taken into account (Fig. 4). The amplitude and phase of the sources for each frequency are extracted from frequency domain signals. Then, the sources are connected to the geometry model in order to achieve a field computation frequency by frequency because the equivalent scheme is frequency dependent.

The main advantage of this process is the fact that very complex topologies can be modeled in conducted and radiated frequency ranges. Thanks to the two presented modeling methods (PEEC and AMLFMM) and to the dedicated tool InCa3D, the applications are not limited to academic and/or simple structures like choppers [1-3]. Multilayer layouts with complex topologies have been modeled too [6]. Industrial power electronic structures have been simulated and all their parasitic elements have been considered in order to fit the model with measurements in high frequencies.

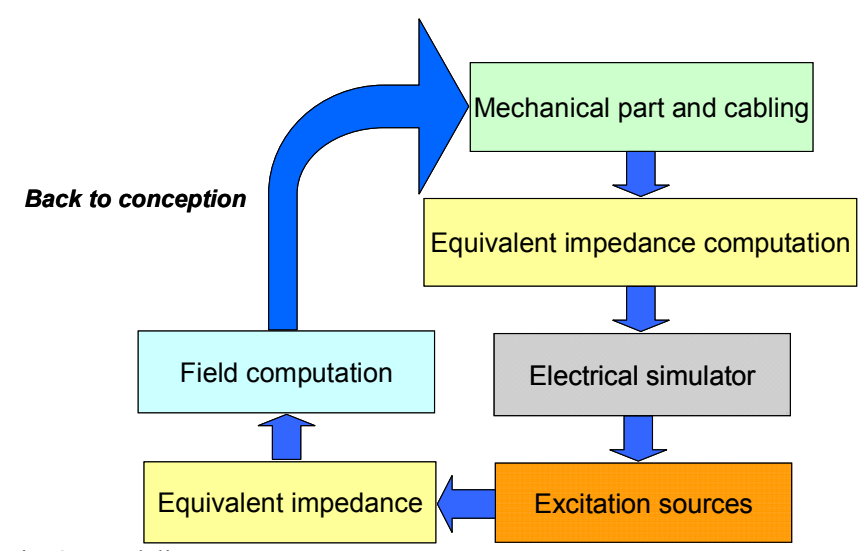

Fig. 3. Modeling process

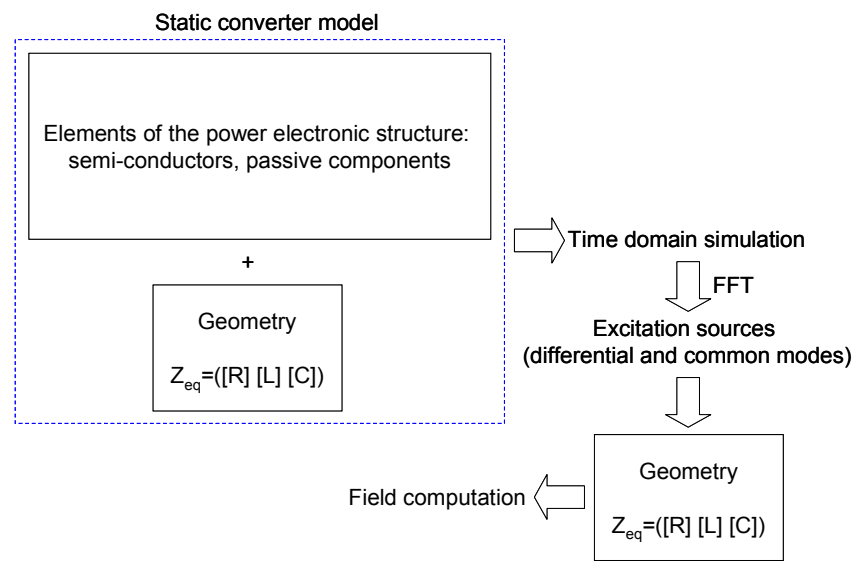

Fig. 4. Extraction of the differential and common mode sources 
As mentioned before, the non linearity is taken into account with time domain simulations. By this way, all the real excitation sources are plugged to the adapted PEEC model.

This point is very important and reveals why such EMC studies can be very complex.

In the following part, the modeling process is applied to an academic power electronic structure. The aim is to validate the process and to show the results obtained by modeling of conducted and radiated perturbations.

\section{ACADEMIC APPLICATION: BOOST CHOPPER}

The modeling process described in the previous section is applied to a Boost converter. Both common mode currents and electric field are modeled and compared with measurements.

\section{A. Presentation}

The converter is placed at $28 \mathrm{~mm}$ above a copper plane to fix its electromagnetic environment. The differential mode current loop and the floating potential, source of the common mode currents, are easily identified (Fig. 5). The common mode currents and the electric field, for standards considerations, have been measured [2] (Fig. 6 and Fig. 7). The electric field of the Boost converter has been measured at three meters with a biconical antenna in a semi-anechoic chamber from $30 \mathrm{MHz}$ to $200 \mathrm{MHz}$.

\section{B. Equivalent electrical circuit}

The resistive, inductive and mutual parts have been computed using PEEC method with InCa3D (Fig. 8). The capacitive part has been extracted from AMLFMM with Flux3D [17] (for the meshing construction) and a java code (for the solving) (Fig. 9). Then, the equivalent impedance has been imported into Saber simulator (Fig. 10).

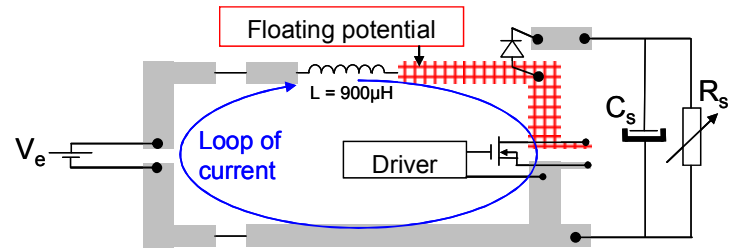

Fig. 5. Boost converter

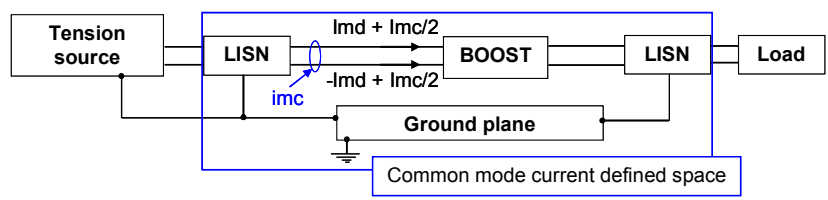

Fig. 6. Set up for common mode current measurement

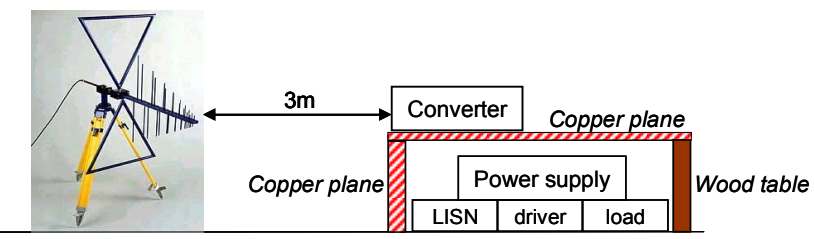

Fig. 7. Set up for electric field measurement

The ( $\mathrm{R}, \mathrm{L}, \mathrm{M})$ PEEC model is contained in a macro-block. The capacitive model is added manually. The automation process is in progress at the Cedrat [17] in collaboration with G2Elab [12]. Time domain simulations are done with small time steps (less than 1ns) in order to extract correct values in high frequencies. The common mode currents are generated during the switching edges. The extraction of the differential mode sources requires a time of simulation equal to 10 switching periods at least. In consequence, the time step must be adapted to the type of excitation source which is extracted.

\section{Results}

The common mode currents are simulated when the switch is turned off and on [2]. First, the switching edges have been modeled (Fig. 11). The simulations are in good agreements with the measurements. From this point, the common mode currents have been simulated too (Fig. 12). The results show good agreements with measurements.

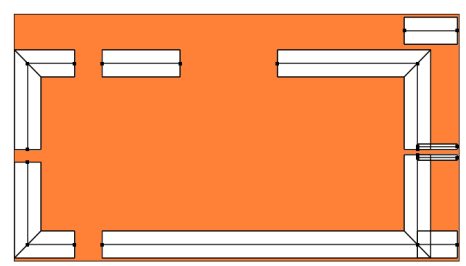

Fig. 8. Geometry in InCa3D

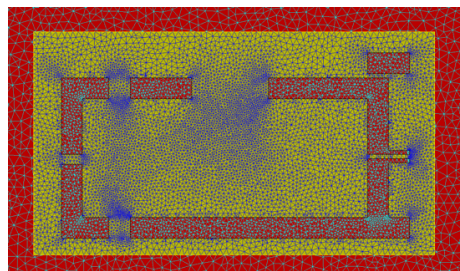

Fig. 9 Meshed geometry in Flux3D

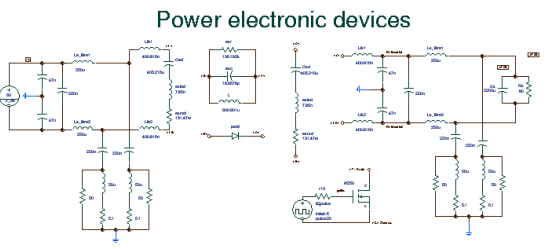

( $R, L, M)$ model: PEEC method

Capacitive model: ALFMM

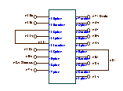

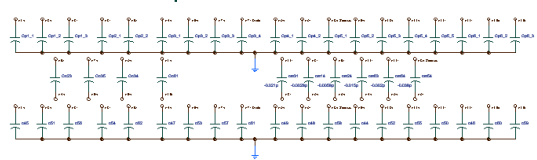

Fig. 10. Electrical circuit with parasitic elements in Saber simulator

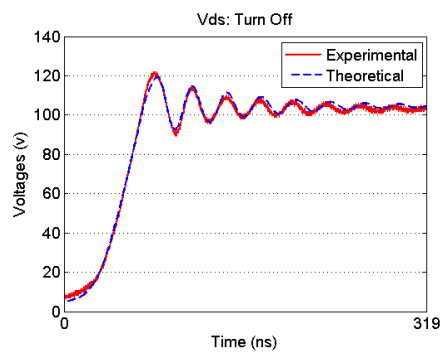

Fig. 11. Drain to source switch voltage

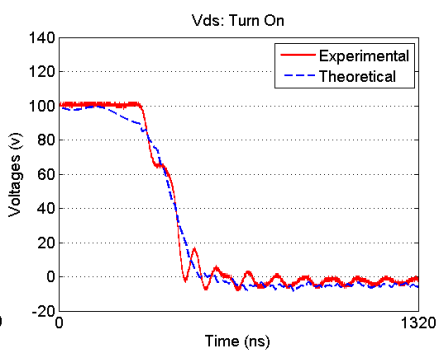

Time (ns) 

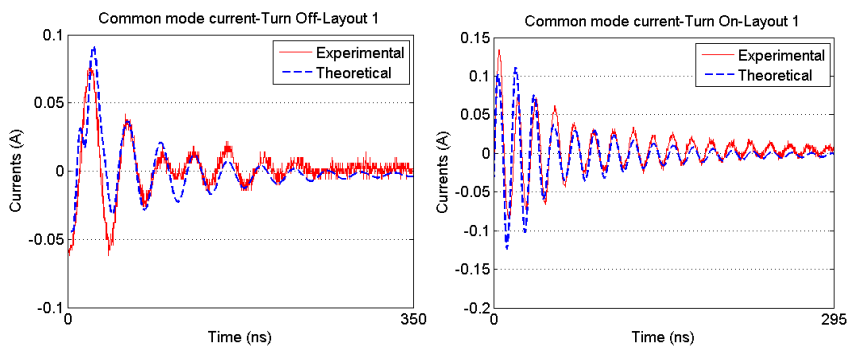

Fig. 12. Common mode currents

The amplitudes and frequencies are very close between the experimental result and the model. In conclusion, knowing all the differential and common mode currents, it is now possible to compute the far radiated electric field (Fig. 13).

The model is then accurate. The equivalent circuit and more particularly the capacitive model are well described. Indeed, the far field is more correlated to the common mode currents [2,7]. The main disadvantage here is the fact that high frequencies results are obtained thanks to important time and memory consuming due to the very small time step.

Even if the modeling process has been applied with success to a power electronic structure for conducted and radiated EMC modeling, it is now important to demonstrate that this method can be used for EMC modeling of complex industrial power electronic structures. In the next section, the modeling of an industrial variable speed drive is presented.

\section{APPLICATION TO AN INDUSTRIAL VARIABLE SPEED DRIVE}

\section{A. Presentation}

The studied structure is a commercialized three-phase motor drive of Schneider and Toshiba Inverter Europe (STIE) [18]. A three-phase common mode filter is connected to a power module including rectifier and inverter (Fig. 14). Thanks to a switch SW100 it is possible to connect or not the earth. The driver has bottom-bottom connectors: inputs (L1, L2 and L3) and outputs (U, V and W) are placed on the same side. Due to thermal constraints, the layout is composed of four layers. The plus of the DC bus is named PA. A cable connects PA to the DC bus capacitors. An inductance $\mathrm{L}_{\mathrm{opt}}$ can be added in order to filter parasitic currents (Fig. 14). PC is the minus of the DC bus. The floating potentials $(\mathrm{U}, \mathrm{V}$ and W) are common mode sources.

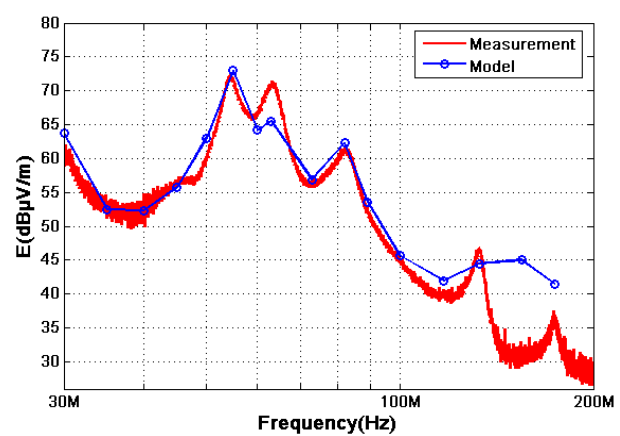

Fig. 13. Electric field

\section{B. Equivalent circuit}

The geometry including the layout and the mechanical part has been designed with InCa3D to extract the resistive and inductive terms using PEEC method and with Flux3D to compute the capacitive terms using AMLFMM (Fig. 15). The equivalent circuit has been imported in Saber (Fig. 16). The differential mode sources are deduced from the simulation of the currents of line, and of the DC bus. The common mode sources are extracted from the values of the floating potentials $\mathrm{U}, \mathrm{V}$, and $\mathrm{W}$.

\section{Results}

The equivalent circuit of such application is complex. In consequence, we have verified that the model is in agreements with the impedance of the variable speed drive. To do that, the resonances in the conducted frequency range have been measured and modeled (Fig. 17 and Table 1).

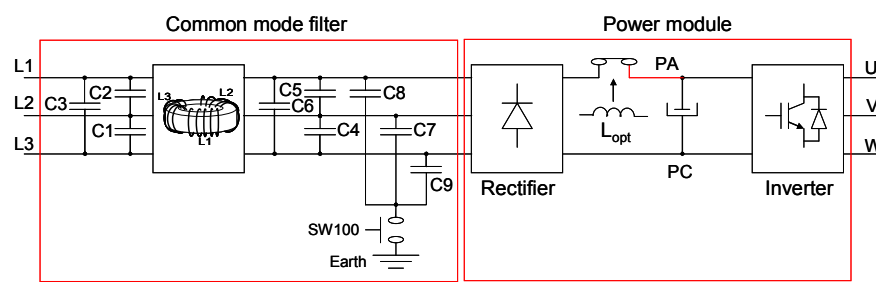

Fig. 14. Variable speed drive structure
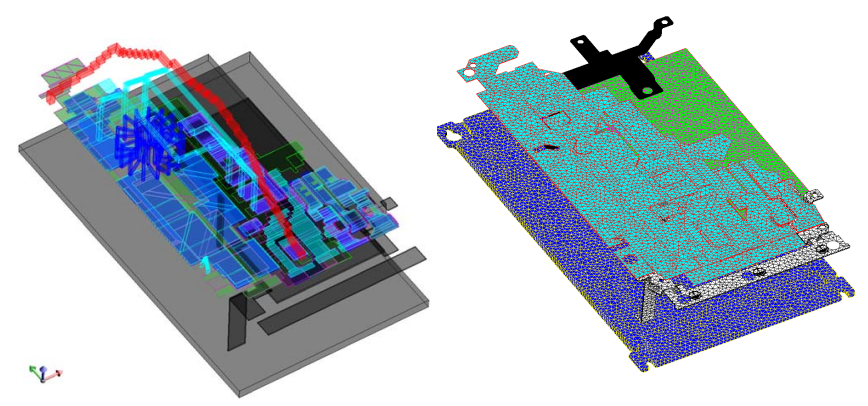

PEEC environment (InCa3D) Capacitive meshes (Flux3D)

Fig. 15. Motor drive models for the extraction of equivalent circuit

(R, L, M) mode
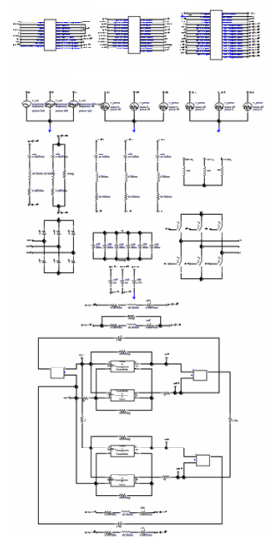

Power electronic devices

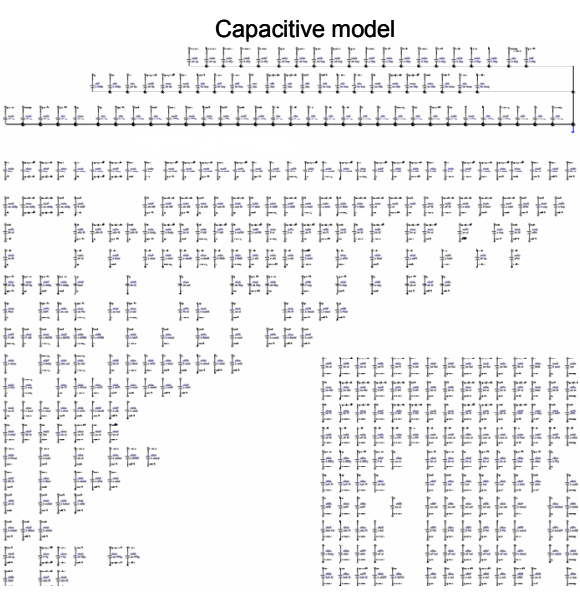

Capacitive mode

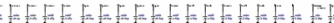

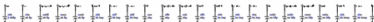

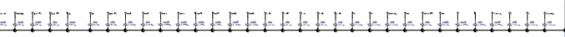

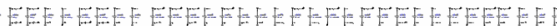

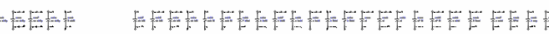
Ther

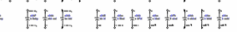

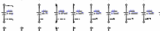

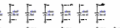

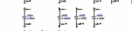
EFEF

Fig. 16. Motor drive model in Saber simulator 
The model has been validated by a harmonic response. The simulated and measured resonances are closed. The resonance F2 which is linked to the cable connecting the converter to the motor does not appear because the cable is not modeled in the simulation.

The magnetic field has been measured and simulated too. The results show $\mathrm{H}(\mathrm{z})$ component at $32 \mathrm{kHz}$ with a good correlation between the cartographies (Fig. 18). This illustrates the fact that the current loops are correctly modeled.

\section{CONCLUSION}

A modeling process combining two integral methods has been presented. An equivalent circuit is extracted from geometries of power electronic structures allowing an EMC prediction in a wide frequency range. The method has been applied to an academic structure showing good agreements with measurements of conducted and radiated perturbations. The process has been applied to an industrial variable speed drive proving the feasibility on such topologies.

TABLE I

RESONANCES

\begin{tabular}{|c|c|c|c|c|}
\hline Frequencies (in MHz) & F0 & F1 & F2 & F3 \\
\hline Measured & 1.314 & 5.166 & 19.16 & 25.83 \\
\hline Simulated & 1.221 & 5.198 & none & 24.76 \\
\hline
\end{tabular}

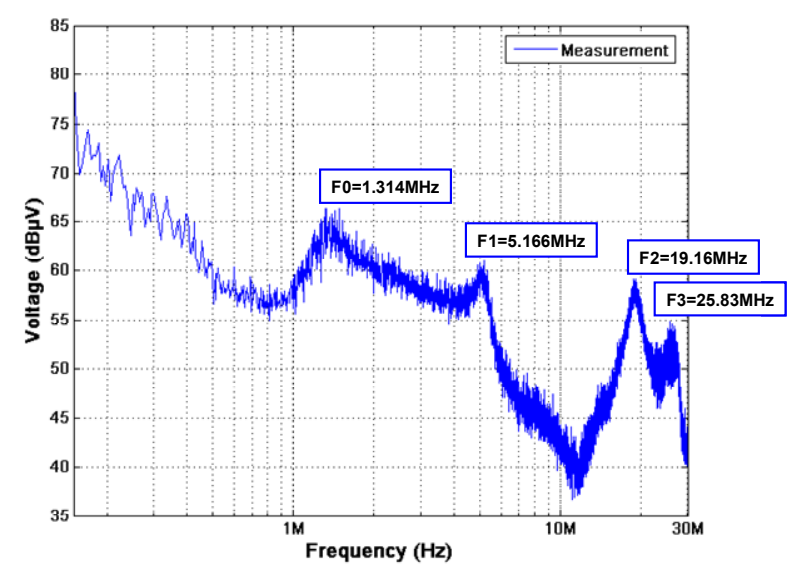

Fig. 17. Measured resonances in the conducted frequency range
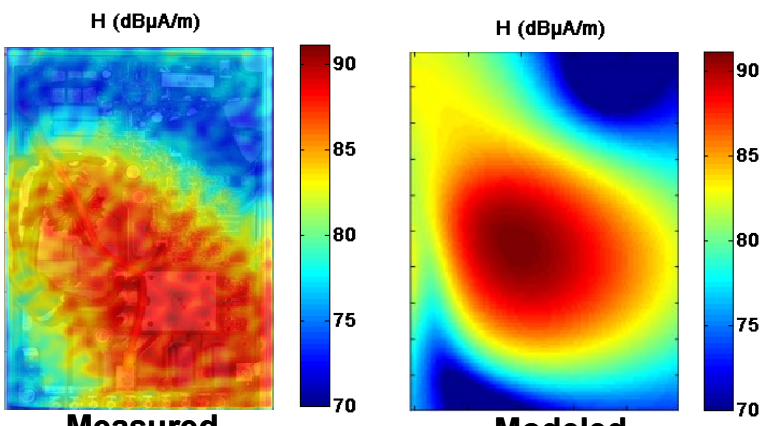

Modeled

\section{ACKNOWLEDGMENT}

We would like to thank Ouafae Aouine, Cécile Labarre and François Costa for the experimental validation of the near magnetic field reduction carried on at the ENSM of Douai.

\section{REFERENCES}

[1] G. Antonini, S. Cristina, A. Orlandi, "A Prediction Model for Electromagnetic Interferences Radiated by an Industrial Power Drive System", IEEE Transactions on Industry Applications, Volume 35, $\mathrm{N}^{\circ}$ 4, pp. 870-876, July/August, 1999.

[2] J. Aimé, J. Roudet, C. Vollaire, P. Baudesson, J. Ecrabey, "Layout Techniques for Reduction of Common Mode Current in Static Converters", IEEE Industry Applications Conference, 2006. FourtyFirst IAS Annual meeting. Conference Record of the 2006 IEEE, Vol. 5, Page(s): 2296-2303, 2006

[3] J. Aimé, J. Roudet, E. Clavel, O. Aouine, C. Labarre, F. Costa, J. Ecrabey, "Prediction and Measurement of the Magnetic Near Field of a Static Converter", IEEE International Symposium on Industrial Electronics, ISIE 2007, pp. 2550-2555, Vigo, Spain, 2007.

[4] B. Revol, J. Roudet, J.-L. Schanen, P. Loizelet, "EMI Study of a Three Phase Inverter-Fed Motor Drives" IEEE Industry Applications Conference, 2004. Thirty-Ninth IAS Annual meeting. Conference Record of the 2004 IEEE, Vol. 4, pp. 2657-2664, 2004.

[5] N. Mutoh, J. Nakashima, M. Kanesaki, "Multilayer Power Printed Structures Suitable for Controlling EMI Noises Generated in Power Converters", IEEE Transactions on Industrial Electronics, Vol. 50, №. 6, pp. 1085-1094, December 2003.

[6] J. Aimé, E. Clavel, J. Roudet, P. Baudesson, "Determination of the Layout Influence on the Effectiveness of a Three-Phase Common Mode Filter by using Equivalent Circuits and PSpice", IEEE International Symposium on Industrial Electronics, ISIE 2008, pp. 1-6, July 2008.

[7] C.R. Paul, "A Comparison of the Contributions of Common Mode and Differential Mode Currents in Radiated Emissions", IEEE Transactions on Electromagnetic Compatibility, Vol. 31, Issue 2, pp. 189-193, May 1989.

[8] J. Aime, T-S. Tran, E. Clavel, G. Meunier, Y. Le Floch, Ph. Baudesson, "Magnetic Field Computation of a Common Mode Filter using Finite Element, PEEC methods and their coupling", IEEE International Symposium on Industrial Electronics, IEEE-ISIE08, 30 June-2 July 2008, Cambridge UK.

[9] A. E.Ruehli, "Inductance Calculations in a Complex Integrated Circuit Environment", IBM Journal on R\&D, September 1972.

[10] L. Greengard, V. Rockhlin, "A Fast Algorithm for Particle Simulations", Journal Comput. Phys. 73, pp. 325-348, 1987.

[11] C. Hoer and C. Love, "Exact Inductance Equations for Rectangular Conductors with Applications to More Complicated Geometries," J. Res. Nut. Bureuu ofStandards-C. Eng. nstrum. 69C, No. 2, 127-1 37 (April-June 1965)

[12] V. Ardon, J. Aimé, O. Chadebec, E; Clavel, E. Vialardi, "MoM and PEEC Method to Reach a Complete Equivalent Circuit of a Static Converter", EMC Zurich, 2009.

[13] J. Carrier, L. Greengard, and V. Rokhlin, "A Fast Adaptive Multipole Algorithm for Particle Simulations", SIAM J. Sci. Statist. Comput., 1988.

[14] K. Nabors, J. Withe, "Multipole-Accelerated Capacitance for 3-D Structures with Multiple Dielectrics", IEEE Transactions on Circuits and Systems, vol. 39, N¹1, Nov. 1992.

[15] A. Buchau, W. M. Rucker, "Capacitance Computation of Thin Conductors with the Fast Multipole Method", International Journal of Applied Electromagnetics and Mechanics, vol.17, 75-89, 2003.

[16] H. Heeb, A. E. Ruehli, "Three-Dimensional Interconnect Analysis Using Partial Element Equivalent Circuits", IEEE Transactions on Circuits and Systems, Vol. 39, No. 11, November 1992.

[17] www.cedrat.com

[18] http://www.schneider-electric.com/sites/corporate/en/home.page

Fig. 18. Radiated magnetic field at $32 \mathrm{kHz}$ 